\title{
Genetic structure of different populations of domestic cat in Spain, Italy, and Argentina at a micro-geographic level
}

\author{
Manuel RUIZ-GARCIA*
}

\begin{abstract}
Ruiz-Garcia M. 1998. Genetic structure of different populations of domestic cat in Spain, Italy, and Argentina at a micro-geographic level. Acta Theriologica 43: 39-66.

Genetic characteristics of the natural populations of domestic cat Felis silvestris f. catus Linnaeus, 1758 were studied in four cities (Barcelona, Catalonia; Palma on Majorca, Balearic islands; Rimini, Italy; Buenos Aires, Argentina) at microgeographic level. The application of different analytical techniques in different population structures (colonies and subpopulations) showed that the degree of genetic differentiation between cat population within these cities was very low, especially when it was compared with the genetic heterogeneity found for other mammals (Nei's and hierarchical gene diversity analyses and estimates of theoretical gene flow). The theoretical gene flow was very high, being $F$, catus in these urban contexts, in a situation very near to panmixia where there was very little spatial genetic structuration and heterogeneity with independence of the cities analyzed. Generally, the genetic structure of these four cat populations showed to be very similar although there were noteworthy ecological differences among the four cities analyzed. This means that the cat population dynamics in diverse cities should be affected by the same demographic and genetic parameters. Only, with certain spatial techniques, the Buenos Aires's cat populations showed some differences in some spatial autocorrelation correlograms with regard the other three cat populations analyzed.
\end{abstract}

CIGEeM., Avd. Virgen Montserrat 207 Sexto primera, Barcelona 08041, Spain

Key words: cats, population genetics, spatial structure, microevolutionary level

\section{Introduction}

The study of the genetics of the domestic cat Felis catus $f$. catus Linnaeus, 1758 populations using the allele frequencies based on the study of certain morphological characters (coat colour and tabby, hair length and some skeletal abnormalities) began with Searle (1949). From the first published study until present, more than 300 populations have been studied. Nevertheless, all these studies showed the genetic relationship between different cat populations in different parts of the World at macrogeographic level. Only recently investigations explaining the possible genetic structure of the cat populations at microgeographic level (colonies and/or subpopulations within the cities) have appeared using genetic and

*Correspondence address: Unidad de Genética (Biología Evolutiva), Departamento de Biología, Facultad de Ciencias, Pontificia Universidad Javeriana, Cra 7a No 43-82, Bogotá D.C. Colombia; e-mail: mruiz@javercol.javeriana.edu.co 
mathematical analyses (Ruiz-Garcia 1991, 1993, 1994a, b, 1997b, c, Ruiz-Garcia et al. 1995, Ruiz-Garcia and Klein 1997).

At the macrogeographic level, some genetic relationships have been detected between the "genic pool" of cat populations whose associated human populations have been commercially related in the past (Todd 1977a, 1978, Lloyd 1985, 1987, Ruiz-Garcia and Alvarez 1996, 1997). For this reason, human commercial flows seem to be the fundamental cause to explain the genetic profiles of different cat populations ("Historical Migration Hypothesis"). Together with this idea, the concept of effective population changing from small to large size also seems to be very important explaining certain present gene frequencies (Morrill and Todd 1978, Anderson and Jenkins 1979, Ruiz-Garcia 1991, 1993, 1994a, b, 1997a, Kajon et al. 1992). Other factor like selection dependent on ecological parameters (Watanabe 1983, Lloyd 1985) have significant importance. At microgeographic level, the causes which modulate the gene frequencies in cat colonies or subpopulations should be more complex to determine, and they can change from one population to another. Moreover, they should be of very different nature to those determined at macrogeographic level. The aim of this work is to analyze what possible basic causes may explain the present spatial distribution and variance of the gene frequencies at two sample populational levels (colonies and subpopulations) within a group of cities with different characteristics. The determination, for instance, of the gene flow can be very important to determine if the expansion of an infective disease should be very rapid in a cat population (O'Brien 1986). The cities chosen for carrying out a genetic microgeographic analysis were: Barcelona and Palma Majorca (Iberian Peninsula and Balearic islands, Spain, Europe), Rimini (Italy, Europe) and Buenos Aires (Argentina, South America).

\section{Material and methods}

This study was done from 1989 to 1994 . Two population sampling levels within the cities were defined: (1) Colonial sampling level. Cats observed at fixed locations and which probably consist of a lot of phylopatric female groups inhabiting a small range and clearly separated from other such populations by short geographical distances (between $500 \mathrm{~m}$ and $2 \mathrm{~km}$, approximately) have been denominated colonies. Defined in this way, the number of colonies in this study was: Barcelona, 11 colonies; Palma Majorca, 10 colonies; Rimini, 11 colonies and Buenos Aires, 7 colonies. (2) Subpopulation sampling level. A set of colonies inhabiting neighbouring areas have been joined representing subpopulations. These areas were isolated from each other by distance and/or by a high number of roads with intense traffic. In some cases, a colony can coincide with a subpopulation. The subpopulation number was 5 (Barcelona), 6 (Palma on Majorca), 6 (Rimini) and 4 (Buenos Aires). In each city studied, each sampled cat was recognized by a photographic register. The geographic situation of these sampling colonies and subpopulations in the cities studied, are shown in Fig. 1.

The phenotypes of the cats were recorded directly from observation of the animals and the genetic nomenclature used is in accordance with the Committee on Standardized Genetic Nomenclature for Cats (1968). The 7 genetic haracteristics studied here included: $O(O, o$; orange vs nou-orange) which is a sex-linked character and the autosomal characters $A\left(A, a\right.$; agouti vs non-agouti), $T\left(T^{a}, t^{+}, t^{b}\right.$; Abyssinian vs mackerel or stripped vs blotched tabby), $D(D, d$; full colour vs dilution), $L$ ( $L, l$; short 

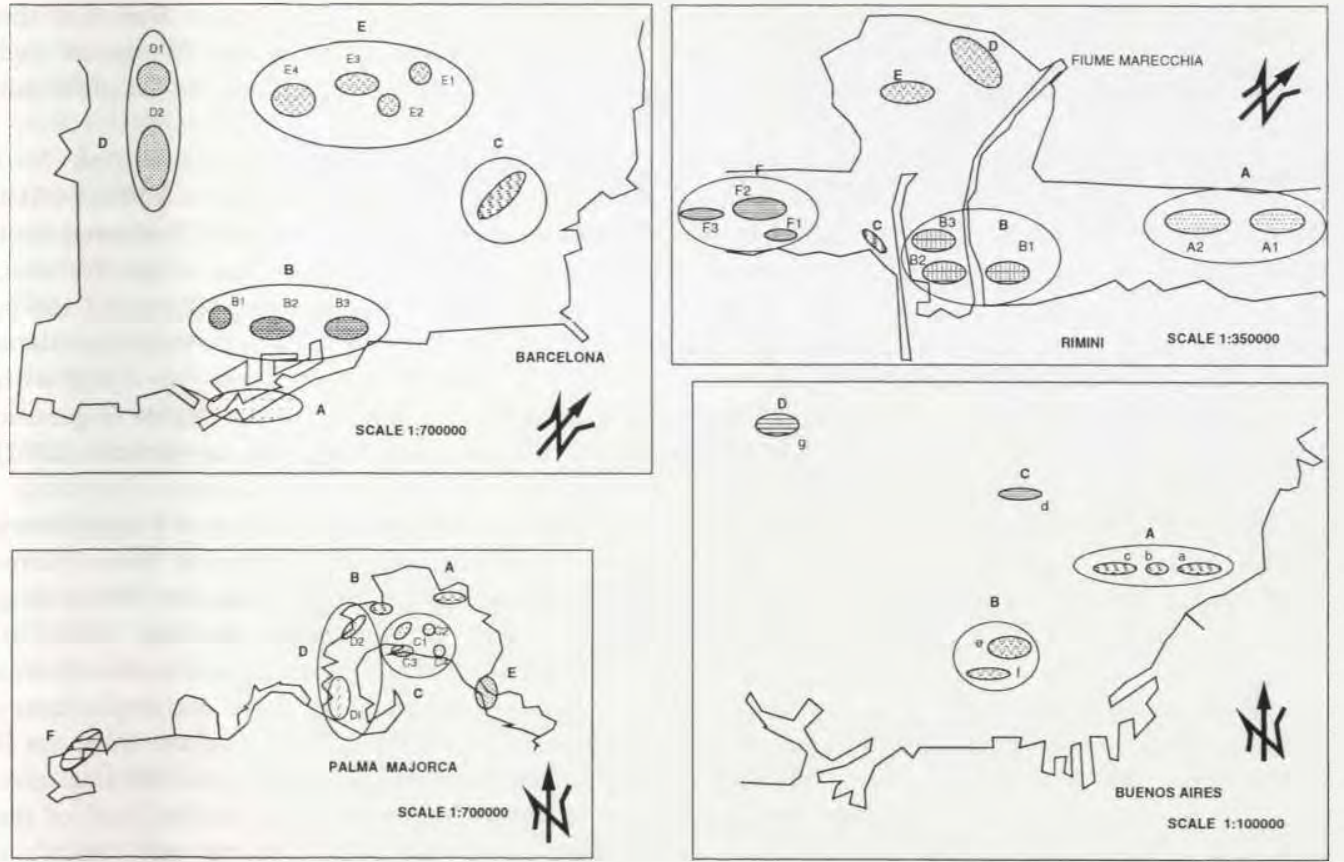

Fig. 1. Mapes of the different cities studied and localization of the cat colonies and subpopulations analyzed.

hair vs long hair), $S$ ( $S, s$; piebald white spotting vs non piebald white spotting) and $W(W, w$; dominat white vs non dominant white). The inheritance of these characters have been previously discussed in detail by Robinson (1977), Wright and Walters (1982) and Ruiz-Garcia (1994a). These characters are unlinked between them. The $\mathrm{p}(O)$ frequency has been calculated using the maximun-likelihood formulas of Robirson and Silson (1969) and Robinson (1972) assuming a sex-ratio 1:1, $\mathrm{p}(O)=$ $(2 \mathrm{a}+\mathrm{b}) / 2 \mathrm{~N}$, where $\mathrm{a}$ is number of orange $(O / O$ and $O /-), \mathrm{b}$ is number of tortoiseshell phenotypes $(O / o)$, and $\mathrm{N}$ is total sample size. The other allele frequencies were calculated using the Hardy-Weinberg equilibrium formulas (Borodin et al. 1978).

Nei (1973) geric diversity analysis at both population levels with the following statistics were obtained: $H_{t}$ - genic diversity in the total population, $H_{s}$ - average gene diversity within subpopulations, $D_{s t}$ - average gene diversity between subpopulations, $G_{s t}$ - gene differentiation between subpopulations relative to the gene diversity in the total population, $\mathrm{Dm}$ - absolute intersubpopulational gene diversity. As I defined total population, subpopulation and colony, a hierarchical gene diversity analysis was conducted (Nei 1973, 1987). For this reason, the following statistics were calculated: $H_{c}$ - average gene diversity within colonies, $D_{c s}=H_{s}-H_{c}$ - average gene diversity between colonies relative to the gene diversity in the subpopulations, $G_{c s}(\mathrm{t})=D_{c s} / H_{t}$ - the relative degree of gene differentiation attributable to colonies within subpopulations relative to the gene diversity in the total population, $G_{c s}=D_{c s} / H_{s}$; genic differentiation attributable to colonies within subpopulations relative to the subpopulational gene diversity). These statistics satisfy the following relation: $H_{t}=H_{c}$ $+D_{c s}+D_{s t}$. If we cbviate the subpopulational sampling structure level, we also get the statistics: $D_{c t}$ - average gene diversity between colonies and $G_{c t}$ - gene differentiation between colonies relative to the gene diversity in the total population, being $H_{t}=H_{c}+D_{c t}$. All these statistics have been calculated using weighed mean and variances (Workman and Niswander 1970). 
A $\mathrm{R} \times \mathrm{C}$ contingency table was used to determine significant genetic heterogeneity from 0 of the allele frequencies for each locus in the colonies and subpopulations within a city (Workman and Niswander 1970). All means and variances obtained in this study were weighed by the different sample sizes,

Using these genetic differentiation coefficients, I calculated theoretical estimates of gene flow $(\mathrm{Nm})$ at colony and subpopulation levels. This can be calculated using the expression $N m=\left[\left(1 / G_{s t}\right)-1\right] / 4$ (Wright 1969). This is an estimate based on an infinite island model. Nei et al. (1977) showed that this method to estimate $\mathrm{Nm}$ is subject to error if the number of the subpopulations is low. For this, it is possible to calculate $\mathrm{Nm}$ estimates by means of a $n$-dimensional island model (Takahata 1983), $N m=\left[\left(1 / G_{s t}\right)-1\right] / 4 \alpha$, where $\alpha=[n /(n-1)]^{2}$ and where $n$ is the number of colonies or subpopulations considered (Slatkin 1985b) and with alleles near the neutral state with a mutation rate $u$ and with $u \ll m$ (migration rate per generation) (Slatkin and Barton 1989). To analyze the degree of genetic contribution of the colonies within the subpopulations and at total level, the Lewontin's (1972) hierarchical method was applied.

The analytic method of spatial distribution and variation of the genetic characters which allows us to make inferences of the microevolutionary processes which have taken place at these microgeographic levels is a spatial autocorrelation analysis (Sokal and Oden 1978, Sokal and Wartenberg 1983, Sokal et al. 1987, 1989, Ruiz-Garcia and Klein 1997, and Ruiz-Garcia and Jordana 1997a, b). This analysis was only applied at colony level because the number of subpopulations in each city was too small. There are some basic procedures which must be performed to carry out evolutionary inferences: (a) Application of a statistical heterogeneity test. I used the $\chi^{2}$-test obtained from the $\mathrm{R}$ $\times \mathrm{C}$ contingency table analysis. (b) Computation of the autocorrelation coefficients and correlograms. Two statistics were used to evaluate spatial autocorrelation of the seven genes studied and of the mean expected heterocigosity (genic diversity; $H_{e}$ ). They were Moran's $I$ statistic and Geary's $c$ coefficient. To carry out this type of studies the populations must be connected using some type of network which simulates as realistically as possible the sort of relationships which exists between them. Some of them are the Gabriel and Sokal (1969) network, the "Minimum spanning tree" network (Rohlf 1970) or the Delaunay's triangulation with elimination of the crossing edges (Isaaks and Srivastava 1989). However, as the cat populations within the cities seem to be distributed near to an island model (gene flow is not dependent of the geographical distances), I connected all pairs of localities in the different specified distance classes. Nevertheless, all these networks were also applied and they offered very similar results that those obtained with this last technique. Moreover, the connection matrix employed was binary due to the lack of knowledge and difficulty in postulating reasonable wheights in this study. At this colony level, I defined 5 distance classes $(D C)$. The upper geographic limit for the specified distance classes for the different analyzed populations were the following: Barcelona: 1971, 4015, 5126, 5968 and 7306 meters; Palma Majorca: 1158, 1757, 2642, 4227 and $12482 \mathrm{~m}$; Rimini: 1565, 2185, 3067, 4936 and $9480 \mathrm{~m}$; Buenos Aires: 1000, 4254, 4715, 5870 and $10510 \mathrm{~m}$. All these particular geographic distances were chosen to optimize the allocation of locality pairs (an equal number of point pairs for distance class) among each distance classes. To determine the statistical significance for autocorrelation coefficients, the Bonferroni procedure (Oden 1984) was used. The Bonferroni's multiple method (Miller 1980, Hochberg 1988) were used to determine a new significance level with this criteria $[\alpha=0.007(0.05 / 7)]$. Other spatial autocorrelation analyses with different number of distance classes were performed. In all cases, the same results were obtained. For this reason, only the quoted analysis is showed. (c) Analysis of similarity of correlograms. To investigate the similarity between the correlograms, I computed the matrices of average Manhattan distances (Sneath and Sokal 1973) between the 7 genetic variables analyzed in every population. This analysis was useful to investigate whether every one of the genetic variables suffered the same evolutionay action or, if on the contrary, every variable was under the pressure of different evolutionary events. Sokal and Wartenberg (1983) and Sokal et al. (1989) showed with simulation studies that pairs of correlograms generated by the same spatial processes had average Manhattan distances lower than 0.1 for the case of Moran's $I$ statistic. Nevertheless, I considered the percentage 
of values of the Manhattan distance with values lower than 0.2 to test for the existence of significant differences as to the homogeneity of correlograms of the various genetic variables studied in the different poptations because there were not enough differences for the value 0.1 obtained by Sokal and collaboraiors. To clusterize these results, I used UPGMA procedure (Sneath and Sokal 1973).

An alternative method used to detect genetic relationship between localities within these cat populations was Mantel's test between the genetic distance matrices (Nei 1972) and the geographic distance matrces (Mantel 1967, Hubert et al. 1981, Hubert and Golledge 1982). In the present work, the Mantel's statstic was normalized using the Smouse et al. (1986) technique, which converts the Mantel's statistic into a correlation coefficient. Using a Monte Carlo simulation (2000 permutations) and using an approximate Mantel's $t$-test, the significance of the obtained correlations was tested to indicate a possible global tendency of spatial autocorrelation between the localities studied.

A principal component analysis with the allele frequencies in every city was performed. In this way, possibly intercorrelated variable sets were transformed to a set of independent variables called principal comporents. The first principal component contributes the most to explain the total variance, the second principal component contributes the most to explain the remainder variance and, so, on with the rest of the components (Harris 1985). The eigenvalues of each variable could be seen as a percentage if the total variability explained for the principal component. Here, Kaiser's rule (Kaiser 1960) was applied because only those principal components whose eigenvalues are higher than the unity ( 1 were considered. I was especially interested in the analysis of the correlations at each locality with the two first principal components ( $Q$ type). This correlations were submitted to a spatial autocorreation analysis to observe whether there was a substancial differentiation in the spatial distribution of these correlations in the cat populations studied.

\section{Results}

The mean rample size of the colonies studied was the following: $64.45 \pm 17.72$ in Barcelona, 46.40 \pm 12.91 in Palma Majorca, $46.54 \pm 11.84$ in Rimini, and $54.28 \pm 22.40$ in Buenos Aires. The sample size values were not significantly different. The geographic mean distance between all the colony pairs of the respective populations analyzed were $4212,3780,3176$, and $4930 \mathrm{~m}$ (Barcelona, Palma Majorci, Rimini and Buenos Aires, respectively). The average sample sizes of the subpoptlations were $141.80 \pm 54.74$ in Barcelona, $77.33 \pm 33.20$ in Palma Majorca, 85.3 \pm 29.12 in Rimini, and $95.00 \pm 45.66$ in Buenos Aires. The average geographical istances between all subpopulation pairs were 4788, 5361, 3071, and $6250 \mathrm{~m}$, espectively.

\section{Analysis of Nei gene diversity}

Colonial sampling level

The analyss of $G_{c t}, G_{c t(d)}$ and $D m$ (Table 1) showed that genetic differentiation between cat conies in Barcelona, Palma Majorca, Rimini, and Buenos Aires was very similar, and this differentiation was very small (much smaller than the one observed in otier mammals). It was observed in all populations that total genic variance $\left(H_{t}\right)$ vas explained fundamentally by differences between the individuals within the colnies $\left(H_{c}\right)$, as the intercolonial differentiation grade $\left(D_{c t}\right)$ was of a very short rarge. The direct $G_{c t}$ statistic (Table 1) showed that between 95 and $97 \%$ of the totl genetic variability was situated within colonies. Barcelona and 
Table 1. Analysis of gene diversity, genetic heterogeneity and theoretical gene flow in cat sampling colonies from Barcelona, Palma Majorca, Rimini and Buenos Aires. The sampling subpopilational level was excluded in this analysis. $G_{c t}$ - gene differentiation between colonies in the total posulation, $\mathrm{Dm}$ - absolute intercolonial gene diversity, $\mathrm{Nm}$ - gene flow. ${ }^{*}-\alpha=0.05$ for individual sigrificance. $\&-\alpha^{\prime}=0.007$ for Bonferroni's multiple test probability.

\begin{tabular}{|c|c|c|c|c|c|c|}
\hline Locus & $G_{c t}$ & $\chi^{2}$ & $\mathrm{df}$ & Dm & $N m_{G c t}$ & $N_{G c t \alpha}$ \\
\hline \multicolumn{7}{|c|}{ BARCELONA } \\
\hline$O$ & 0.0228 & $30.6 * \&$ & 10 & 0.0067 & 10.71 & 8.86 \\
\hline$a$ & 0.0048 & 5.1 & 10 & 0.0027 & 51.83 & $4: .84$ \\
\hline$t^{b}$ & 0.0707 & $56.4^{*} \&$ & 10 & 0.0308 & 3.15 & ¿.60 \\
\hline$d$ & 0.0235 & $32.1 * \&$ & 10 & 0.0100 & 10.39 & 8.58 \\
\hline$l$ & 0.0609 & $95.9 * \&$ & 10 & 0.0141 & 3.86 & 8.19 \\
\hline$S$ & 0.0175 & $23.3^{*}$ & 10 & 0.0076 & 14.04 & $1 . .60$ \\
\hline W & 0.0144 & 19.0 & 10 & 0.0001 & 17.11 & $1+.14$ \\
\hline \multirow[t]{2}{*}{ Mean } & 0.0307 & $262.5^{*} \&$ & 70 & 0.0103 & & \\
\hline & \pm 0.0125 & & & \pm 0.0051 & & \\
\hline \multicolumn{7}{|c|}{ Direct values for 7 loci: $G_{c t}=0.0312, N m_{G c t}=7.75, N m_{G c t \alpha}=6.41$} \\
\hline \multicolumn{7}{|c|}{ PALMA MAJORCA } \\
\hline$O$ & 0.0540 & $48.7 * \&$ & 9 & 0.0189 & 4.38 & 3.55 \\
\hline$a$ & 0.0266 & $20.2^{*}$ & 9 & 0.0121 & 9.13 & 7.40 \\
\hline$t^{b}$ & 0.0612 & $30.1^{*} \&$ & 9 & 0.0302 & 3.84 & 3.11 \\
\hline$d$ & 0.0172 & 14.7 & 9 & 0.0085 & 14.31 & 11.59 \\
\hline$l$ & 0.0999 & $91.7 * \&$ & 9 & 0.0399 & 2.25 & 1.82 \\
\hline$S$ & 0.0326 & $28.9 * \&$ & 9 & 0.0130 & 7.43 & 3.02 \\
\hline$W$ & 0.0084 & 6.8 & 9 & 0.0000 & 29.49 & 23.88 \\
\hline \multirow[t]{2}{*}{ Mean } & 0.0428 & $241.1 * \&$ & 63 & 0.0175 & & \\
\hline & \pm 0.0157 & & & \pm 0.0067 & & \\
\hline \multicolumn{7}{|c|}{ Direct values for 7 loci: $G_{c t}=0.0471, N m_{G c t}=5.05, N m_{G c t \alpha}=4.09$} \\
\hline \multicolumn{7}{|c|}{ RIMINI } \\
\hline$O$ & 0.0299 & $26.9 * \&$ & 10 & 0.0074 & 8.11 & 6.71 \\
\hline$a$ & 0.0184 & 14.8 & 10 & 0.0089 & 13.34 & 1.02 \\
\hline$t^{b}$ & 0.0552 & $29.3^{*} \&$ & 10 & 0.0282 & 4.28 & 3.54 \\
\hline$d$ & 0.0113 & 9.4 & 10 & 0.0059 & 21.89 & 8.09 \\
\hline$l$ & 0.0718 & $66.9 * \&$ & 10 & 0.0251 & 3.23 & 2.67 \\
\hline$S$ & 0.0159 & 13.9 & 10 & 0.0069 & 15.38 & 2.71 \\
\hline$W$ & 0.0125 & 10.7 & 10 & 0.0003 & 19.70 & 6.28 \\
\hline \multirow[t]{2}{*}{ Mean } & 0.0307 & $171.9^{*} \&$ & 70 & 0.0118 & & \\
\hline & \pm 0.0118 & & & \pm 0.0052 & & \\
\hline \multicolumn{7}{|c|}{ Direct values for 7 loci: $G_{c t}=0.0321, N m_{G c t}=7.53, N m_{G c t \alpha}=6.23$. } \\
\hline \multicolumn{7}{|c|}{ BUENOS AIRES } \\
\hline$O$ & 0.0695 & $50.6 * \&$ & 6 & 0.0231 & 3.35 & 2.46 \\
\hline$a$ & 0.0109 & 6.3 & 6 & 0.0047 & 22.58 & 16.59 \\
\hline$t^{b}$ & 0.1120 & $30.8 * \&$ & 6 & 0.0535 & 1.98 & 1.46 \\
\hline$d$ & 0.0139 & 9.3 & 6 & 0.0078 & 17.75 & 13.04 \\
\hline$l$ & 0.0080 & 5.1 & 6 & 0.0045 & 30.96 & 22.72 \\
\hline$S$ & 0.0235 & $16.4^{*}$ & 6 & 0.0118 & 10.39 & 7.64 \\
\hline W & 0.0128 & 8.7 & 6 & 0.0003 & 19.29 & 14.17 \\
\hline \multirow[t]{2}{*}{ Mean } & 0.0358 & $127.2 * \&$ & & 0.0151 & & \\
\hline & \pm 0.0199 & & & \pm 0.0092 & & \\
\hline \multicolumn{7}{|c|}{ Direct value for 7 loci: $G_{c t}=0.0366, N m_{G c t}=6.58, N m_{G c t \alpha}=4.84$. } \\
\hline
\end{tabular}


Rimini showed intercolonial differentiation estimates slightly lower than the other two populations although without statistic differentiation. With Bonferroni's method, the loci which showed significant heterogeneity were: $O, t^{b}, d$, and $l$ in Barcelona, $O, t^{b}, l$, and $S$ in Palma Majorca, $O, t^{b}, l$ in Rimini, and $O, t^{b}$ in Buenos Aires. It was noteworthy that the $l$ allele (long hair) was one of those which introduced most genetic heterogeneity in the three European cities studied but, introduced the less genetic heterogeneity in the South-American population.

The analysis of hierarchical gene diversity (Table 2 ) showed $G_{c s}$ values similar in the four populations studied. These values strengthen that most of gene diversity was comprised in small population unities.

The theoretical gene flow estimates $(\mathrm{Nm})$ (Tables 1 and 2) indicated that there was a high gene flow between the cat colonies with regard to the total populations, and between the colonies within the subpopulations. These theoretical gene flow estimates were very similar between the four studied populations among the colonies relative to the total population as well as between the colonies at subpopulation level. The Lewontin's diversity analysis applied to the Barcelona, Palma Majorca, Rimini and Buenos Aires's cat populations showed that the major part of gene diversity was within colonies $(90.60 \%, 91.19 \%, 89.24 \%, 93.10 \%$, respectively) although in a lower grade that those showed by the Nei's method (Table 3).

\section{Subpopulational sampling level}

The analysis of $G_{s t}, G_{s t(d)}, D m$ (Table 4) showed that by increasing the populational sample level, the intersubpopulational genetic differences were even lower than at colony level. For instance, an average subpopulation in the Barcelona's cat population had $99.3 \%$ of the total genic diversity of these population, and, in the case of Palma Majorca, $97.7 \%$ of the total genic diversity was comprised at subpopulation level (both extreme values, respectively). The unique significant difference found between the four populations studied was Barcelona vs Palma Majorca ( $t=1.76, p<0.05$ for $G_{s t}$ and $t=1.92 p<0.05$ for $D m$, respectively). That is, the cat population of Barcelona was significantly more homogeneous than the Palma Majorca population at subpopulation level. With Bonferroni's method, the loci which showed significant heterogeneity were: $l$ in Barcelona, $t^{b}, l, S$ in Palma Majorca, $l$ in Rimini, and $O$ in Buenos Aires.

At subpopulation level, $\mathrm{Nm}$ (Table 4) were higher than at colony level, which was motivated because the effective population sizes at this level were considerably higher than those which were found at colony level. Barcelona was the one which offered the highest theoretical gene flow estimates $\left(N m G_{s t}=31.82 ; N m G_{s t \alpha}=20.36\right)$. Buenos Aires and Rimini showed very similar values of gene flow $\left(N m G_{s t}=17.22\right.$, $N m G_{\text {sto } \alpha}=9.68$ in Buenos Aires and $N m G_{s t}=17.02, N m G_{s t \alpha}=11.82$ in Rimini). Palma Majorca was the population that offered the lowest gene flow ( $N m G_{s t}=$ 8.81 and $\left.N m G_{s t \alpha}=7.28\right)$. Here, there was a noteworthy difference between the 
Table 2. Hierarchical analysis of genetic differentiation and gene flow between sampling colonies and subpopulations in Barcelona, Palma Majorca, Rimini and Buenos Aires cat population. For symbols, see text. * These loci were excluded from the calculations because they offered negative variance components. This was due because in variance component estimation, resulting from the assumption, for calculating purposes, that estimated total variance is divided orthogonally into estimated variance components.

\begin{tabular}{lllll}
\hline Locus & $D_{c s}$ & $G_{c s}(t)$ & $G_{c s}$ & NmGes \\
\hline
\end{tabular}

BARCELONA

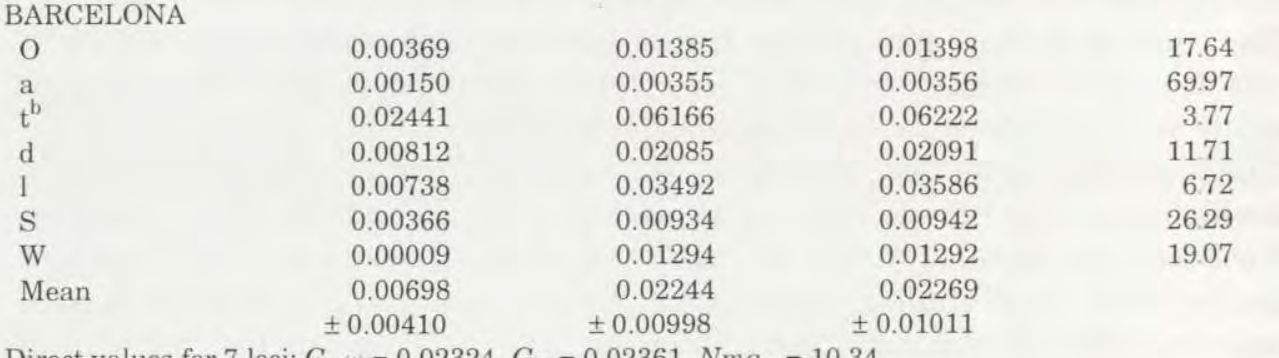

Direct values for 7 loci: $G_{c s(t)}=0.02324, G_{c s}=0.02361, N m_{G c s}=10.34$.

$\begin{array}{lccc}\text { PALMA MAJORCA } & & & \\ \mathrm{O} & 0.01405 & 0.04463 & 0.04490 \\ \mathrm{a} & 0.00324 & 0.00800 & 0.00808 \\ \mathrm{t}^{\mathrm{b}} & 0.00771 & 0.01727 & 0.01811 \\ \mathrm{~d}^{\mathrm{n}} & 0.00735 & 0.01623 & 0.01643 \\ \mathrm{l} & 0.02823 & 0.07551 & 0.08021 \\ \mathrm{~S}^{*} & - & - & - \\ \mathrm{W}^{*} & - & - & - \\ \text { Mean } & 0.01212 & 0.03233 & 0.03355 \\ & \pm 0.00490 & \pm 0.01390 & \pm 0.01476\end{array}$

Direct values for 5 loci: $G_{c s(t)}=0.03599, G_{c s}=0.03697, N m_{G e s}=6.51$.

\begin{tabular}{|c|c|c|c|c|}
\hline \multicolumn{5}{|c|}{ RIMINI } \\
\hline $\mathrm{O}$ & 0.00276 & 0.01231 & 0.01253 & $1 \mathrm{~s} .70$ \\
\hline a & 0.00445 & 0.01017 & 0.01022 & 24.21 \\
\hline$t^{b}$ & 0.02891 & 0.06140 & 0.06194 & 379 \\
\hline d & 0.00511 & 0.01062 & 0.01065 & 2323 \\
\hline 1 & 0.01078 & 0.03323 & 0.03525 & 684 \\
\hline S & 0.00153 & 0.00392 & 0.00397 & 62.79 \\
\hline $\mathrm{W}^{*}$ & - & - & - & - \\
\hline Mean & 0.00896 & 0.02194 & 0.02242 & \\
\hline & \pm 0.00515 & \pm 0.01088 & \pm 0.01107 & \\
\hline Direct v & $G_{c S(t)}=0.026$ & $0.02692, N$ & & \\
\hline BUENO & & & & \\
\hline $\mathrm{O}$ & 0.01036 & 0.03628 & 0.03754 & $€ 41$ \\
\hline a & 0.00008 & 0.00022 & 0.00023 & 1102.21 \\
\hline$t^{b}$ & 0.05494 & 0.12731 & 0.13121 & 1.65 \\
\hline d & 0.00181 & 0.00245 & 0.00248 & $10 c .58$ \\
\hline 1 & 0.00227 & 0.00469 & 0.00471 & 52.77 \\
\hline S & 0.00674 & 0.01571 & 0.01572 & 15.62 \\
\hline W & 0.00003 & 0.00144 & 0.00146 & 171.26 \\
\hline Mean & 0.01080 & 0.02687 & 0.02762 & \\
\hline & 0.00992 & \pm 0.02304 & $=0.02377$ & \\
\hline
\end{tabular}

Direct values for 7 loci: $G_{c s(t)}=0.03022, G_{c s}=0.03066, N_{\text {G }}=7.90$. 
Table 3. Lewontins diversity analysis applied to cat populations from Barcelona, Palma Majorca, Rimini, and Buenos Aires.

\begin{tabular}{|c|c|c|c|}
\hline & \multicolumn{3}{|c|}{ Diversity (\%) } \\
\hline 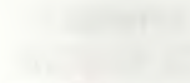 & Within colonies & $\begin{array}{l}\text { Between colonies } \\
\text { in subpopulations }\end{array}$ & Between subpopulations \\
\hline \multicolumn{4}{|l|}{ BARCELONA } \\
\hline$O$ & 96.62 & 2.42 & 0.97 \\
\hline$a$ & 99.67 & 0.26 & 0.005 \\
\hline$t^{b}$ & 87.25 & 11.38 & 1.37 \\
\hline$d$ & 97.75 & 1.96 & 0.29 \\
\hline$l$ & 77.82 & 14.47 & 7.71 \\
\hline$S$ & 98.13 & 1.01 & 0.86 \\
\hline$W$ & 76.94 & 13.70 & 9.36 \\
\hline Mean & $90.60 \pm 4.95$ & $6.46 \pm 3.20$ & $2.94 \pm 1.94$ \\
\hline \multicolumn{4}{|c|}{ PALMA MAJORCA } \\
\hline$O$ & 95.97 & 3.16 & 0.86 \\
\hline$a$ & 95.69 & 2.87 & 1.44 \\
\hline$t^{b}$ & 91.38 & 1.53 & 7.08 \\
\hline$d$ & 97.18 & 1.56 & 1.24 \\
\hline$l$ & 78.19 & 10.52 & 11.29 \\
\hline$S$ & 93.98 & 3.20 & 2.81 \\
\hline$W$ & 85.91 & 6.31 & 7.77 \\
\hline Mean & $91.19 \pm 3.43$ & $4.16 \pm 1.61$ & $4.64 \pm 2.03$ \\
\hline \multicolumn{4}{|l|}{ RIMINI } \\
\hline$O$ & 97.27 & 0.01 & 2.26 \\
\hline$a$ & 97.68 & 1.64 & 0.67 \\
\hline$t^{b}$ & 82.22 & 19.95 & 0.83 \\
\hline$d$ & 99.72 & 0.07 & 0.21 \\
\hline$l$ & 80.86 & 8.61 & 10.53 \\
\hline$S$ & - & - & - \\
\hline W & 77.70 & 15.68 & 6.61 \\
\hline Mean & $89.24 \pm 4.99$ & $7.18 \pm 3.88$ & $3.58 \pm 2.07$ \\
\hline \multicolumn{4}{|c|}{ BUENOS AIRES } \\
\hline$O$ & 91.68 & 1.78 & 6.54 \\
\hline$a$ & 97.98 & 0.63 & 1.39 \\
\hline$t^{b}$ & 78.32 & 12.77 & 8.90 \\
\hline$d$ & 97.63 & 0.58 & 1.79 \\
\hline$l$ & 98.64 & 0.91 & 0.45 \\
\hline$S$ & 98.43 & 1.18 & 0.38 \\
\hline$W$ & 89.05 & 1.31 & 9.64 \\
\hline Mean & $93.10 \pm 3.76$ & $2.74 \pm 2.22$ & $4.16 \pm 2.03$ \\
\hline
\end{tabular}


Table 4. Analysis of gene diversity and gene flow in cat sampling subpopulations fron Barcelona, Palma Majorca, Rimini and Buenos Aires. $G_{s t}$ - gene differentiation between subpopulitions in the total population, $\mathrm{Dm}$ - absolute intersubpopulational gene diversity, $\mathrm{Nm}$ - Gene flow. ${ }^{*}-\alpha=0.05$ for individual significance test, $\&-\alpha^{\prime}=0.007$ for Bonferroni multiple test significance.

\begin{tabular}{lccccrr}
\hline Locus & $G_{s t}$ & $\chi^{2^{\prime}}$ & df & Dm & NmGst & NmGsta \\
\hline BARCELONA & & & & & & \\
$O$ & 0.0089 & $11.39^{*}$ & 4 & 0.0029 & 30.22 & 17.17 \\
$a$ & 0.0013 & 0.64 & 4 & 0.0007 & 486.34 & 121.86 \\
$t^{b}$ & 0.0090 & 5.90 & 4 & 0.0046 & 32.20 & 17.60 \\
$d$ & 0.0026 & 2.66 & 4 & 0.0013 & 129.71 & 60.30 \\
$l$ & 0.0260 & $35.33^{*} \&$ & 4 & 0.0069 & 9.64 & 6.00 \\
$S$ & 0.0082 & $10.42^{*}$ & 4 & 0.0040 & 33.06 & 19.29 \\
$W$ & 0.0014 & 1.07 & 4 & 0.0000 & 208.15 & 114.12 \\
Mean & 0.0082 & $67.42^{*} \&$ & 28 & 0.0029 & & \\
& \pm 0.0043 & & & \pm 0.0012 & &
\end{tabular}

Direct values for 7 loci: $G_{s t}=0.0078, N m_{G s t}=31.82, N m_{G s t \alpha}=20.36$.

\section{PALMA MAJORCA}

$\begin{array}{ll}O & 0.0061 \\ a & 0.0107 \\ t^{b} & 0.0519 \\ d & 0.0119 \\ l & 0.0586 \\ S & 0.0231 \\ W & 0.0055 \\ \text { Mean } & 0.0240 \\ & \pm 0.0206\end{array}$

4.63
7.42
$24.66^{*} \&$
9.93
$53.65 * \&$
$19.77 * \&$
4.15
$124.22 * \&$

5
5
5
5
5
5
5
35

$\begin{array}{rr}49.48 & 28.24 \\ 26.29 & 16.09 \\ 4.76 & 3.17 \\ 22.72 & 14.32 \\ 4.09 & 2.79 \\ 11.09 & 7.33 \\ 55.91 & 31.26\end{array}$

Direct values for 7 loci: $G_{s t}=0.0276, N m_{G s t}=8.81, N m_{G s t \alpha}=7.28$.

$\begin{array}{lr}\text { RIMINI } & \\ O & 0.0175 \\ a & 0.0047 \\ t^{b} & 0.0086 \\ d & 0.0027 \\ l & 0.0571 \\ S & 0.0103 \\ W & 0.0065 \\ \text { Mean } & 0.0153 \\ & \pm 0.0095\end{array}$

$15.39^{*}$
3.06
3.74
1.50
$53.01^{*} \&$
8.61
5.19
$90.51^{*} \&$

$\begin{array}{cr}5 & 0.0047 \\ 5 & 0.0025 \\ 5 & 0.0049 \\ 5 & 0.0016 \\ 5 & 0.0222 \\ 5 & 0.0048 \\ 5 & 0.0002 \\ 35 & 0.0058 \\ & \pm 0.0037\end{array}$

14.00

52.67

28.66

91.44

4.13

24.03

38.41

9.72

36.58

19.91

63.50

2.87

16.69

26.67

Direct values for 7 loci: $G_{s t}=0.0145, N m_{G s t}=17.02, N m_{G s t \alpha}=11.82$.

\section{BUENOS AIRES}

$\begin{array}{lcccccr}\text { BUENOS AIRES } & & & & & \\ O & 0.0333 & 23.72^{*} \& & 3 & 0.0127 & 7.25 & 4.08 \\ a & 0.0105 & 6.01 & 3 & 0.0051 & 23.57 & 13.26 \\ t^{b} & 0.0297 & 7.44 & 3 & 0.0171 & 8.16 & 4.59 \\ d & 0.0119 & 7.84^{*} & 3 & 0.0076 & 20.72 & 11.66 \\ l & 0.0053 & 3.10 & 3 & 0.0035 & 46.14 & 25.95 \\ S & 0.0023 & 0.73 & 3 & 0.0013 & 106.87 & 60.11 \\ W & 0.0118 & 7.98^{*} & 3 & 0.0004 & 20.90 & 11.76 \\ \text { Mean } & 0.0149 & 56.83^{*} \& & 21 & 0.0068 & & \end{array}$

Direct values for 7 loci: $G_{s t}=0.0143, N m_{G s t}=17.21, N m_{G s t \alpha}=9.68$. 
sampling colony and subpopulation levels. The sample subpopulation level showed more differences between the populations studied than the colonial level did.

\section{Spatial autocorrelation analysis}

Only at colony level, a spatial autocorrelation analysis was carried out with 5 distance classes (DC) (Fig. 2, only for Moran's $I$ index). The values showed in brackets correspond to Geary's coefficient and the others to Moran's index percentages which showed significant results with $\alpha=0.05$. BARCELONA: Only $5 \%(12.5 \%)$ of the autocorrelation coefficients were significant. Only $12.5 \%$ (12.5\%;

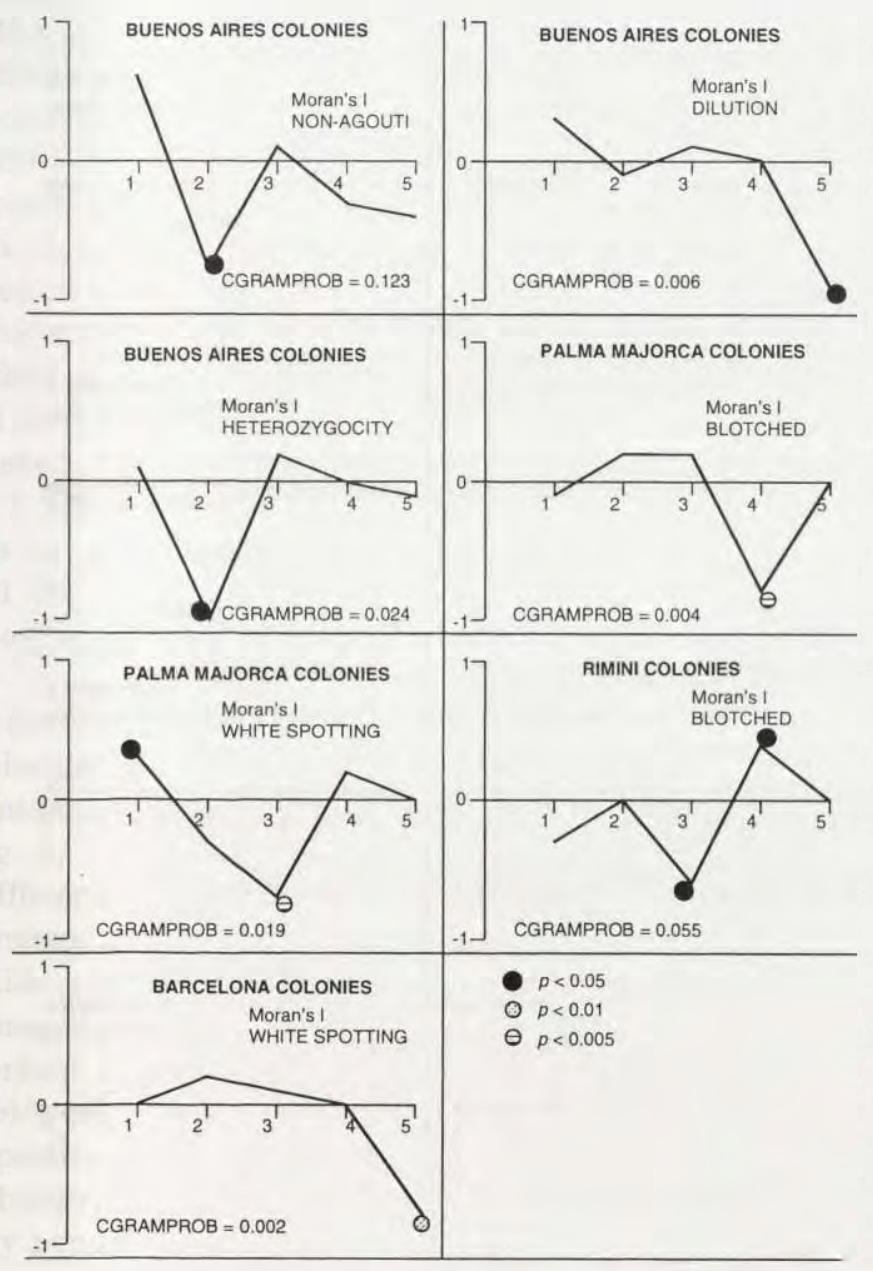

Fig. 2. Significant correlograms obtained in the four cat populations studied at colony level. The overall correlograms for Non-Agouti in Buenos Aires and for blotched in Rimini were not significant but some distance classes were. 
1 variable out of 8 ) of the global correlograms was significant ( $S$ locus showing a significant spatial pattern). All these percentages did not differ significantly from $5 \%$ type I error (Sokal and Rohlf 1981). With the criteria of Bonferroni's multiple test, only $S$ was significant. $75 \%(75 \%)$ of the autocorrelation coefficients were more negative that expected in the $1 \mathrm{DC}$ under the absolute absence of autocorrelation. There was not any spatial structure in the average overall correlogram. PALMA MAJORCA: $17.5 \%(12.5 \%)$ of the autocorrelation coefficients were significant. $25 \%(12.5 \%)$ of the correlograms were significant. These percentages were not significantly different from $5 \%$ type I error. $t^{b}$ and $S$ showed significant patterns resembling circular clines (with Geary's $c$ only $t^{b}$ showed a significant

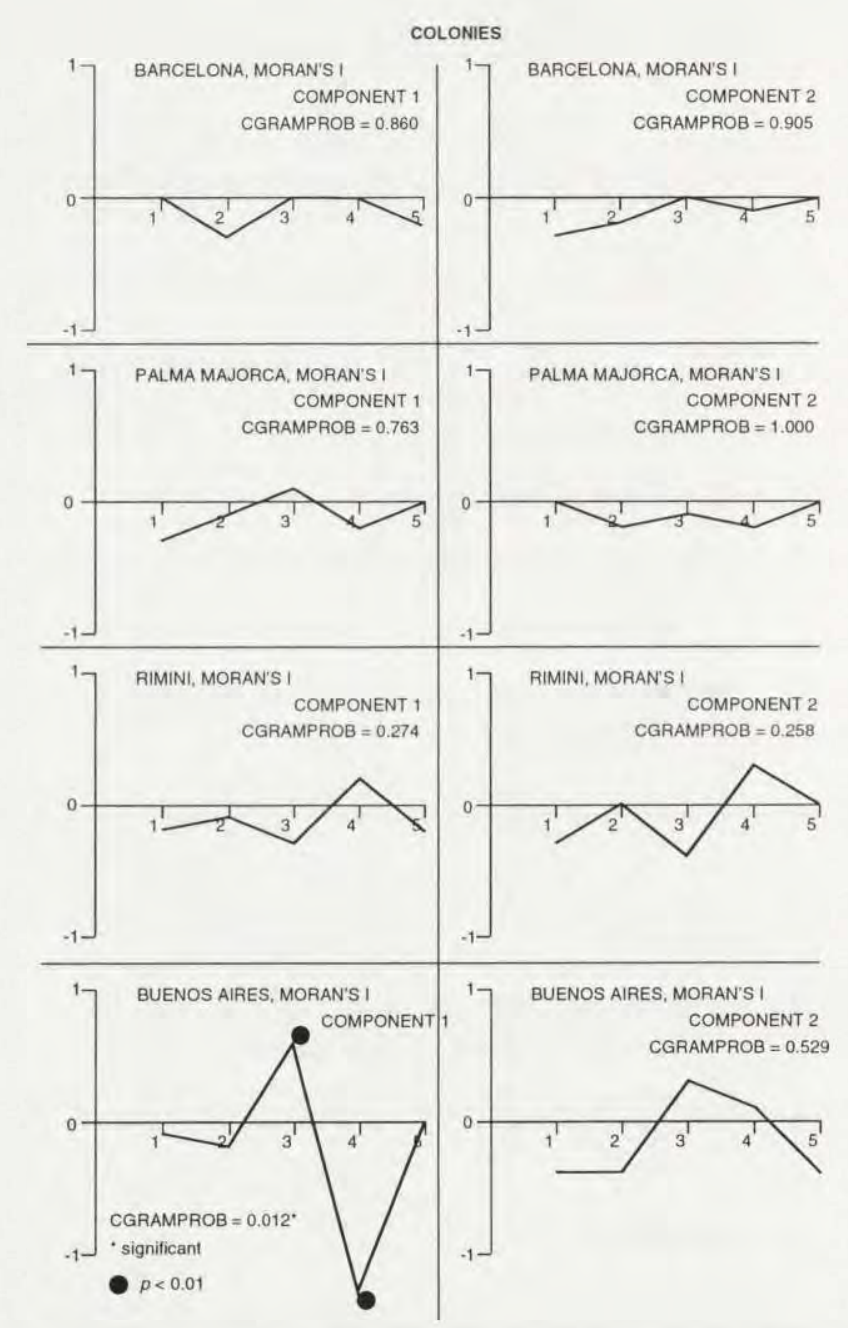

Fig. 3. Correlograms for the correlations of the cat colonies with the two first component principals studied in Barcelona, Palma Majorca, Rimini, and Buenos Aires. 
pattern). With the Bonferroni's multiple tests only $t^{b}$ was significant. The negative coefficient percentage in $1 \mathrm{DC}$ was substantially lower than the negative percentage found in Barcelona, because only its value was $37.5 \%(50 \%)$. There was not any significant spatial structure in the average overall correlogram. RIMINI: $15 \%(12.5 \%)$ of the autocorrelation coefficients were significant. These percentages were not significantly different from 5\% type I error. Moreover, none of these global correlograms were significant $(0 \%)$. With the Bonferroni's multiple test neither loci was significant. $100 \%(100 \%)$ of the autocorrelation coefficients in 1 $\mathrm{CD}$ were more negative than those expected with no existing autocorrelation. There was not any significant spatial structure in the average overall correlogram. BUENOS AIRES: $10 \%(17.5 \%)$ of the autocorrelation coefficients was significant. $25 \%(25 \%)$ of the global correlograms showed statistic significance. The $d$ allele showed a significantly clinal pattern ( $p=0.006$ for Moran's $I$ and Geray's $c$ ) and $H$ showed regional patches ( $p=0.013$ for Moran's $I$ and $p=0.030$ for Geary's $c$ ) (Sokal et al. 1989). The $a$ allele also showed regional patchiness (in 1 DC, it showed a significant positive coefficient and in $2 \mathrm{DC}$ it showed a significant negative coefficient with Moran's $I$ and Geary's $c$ ). If we extract the two $\mathrm{q}\left(t^{b}\right)=0$ values, the $t^{b}$ allele showed a significant clinal pattern ( $p=0.007$ for Moran's $I$ ). It should be the case where more significant spatial genetic structure with $\alpha=0.05$ was found in the four populations analyzed. The percentage of variables with significant overall correlograms was $50 \%$, being this value significantly superior than to $5 \%$ type I error $\left(\chi^{2}=4.06, \mathrm{df}=1, p<0.05\right)$. The percentage of negative coefficients in 1 DC was only $22 \%(25 \%)$. The average correlogram differed in certain aspects to what was observed for the other populations. The average coefficient for $1 \mathrm{DC}$ showed an average positive value, and globally there was a tendency to show a regionally patches pattern $(0.05,-0.33,-0.18,-0.03,-0.35$; Moran's $I$ ).

The spatial autocorrelation analysis applied to the correlations obtained from the individual localities at colonial level with the two first components from the $\mathrm{Q}$ principal component analysis for each of the 4 populations studied, were interesting (Fig. 3, Table 5). In Barcelona, Palma Majorca and Rimini, no autocorrelation coefficient was significant. Neither were the overall correlograms. All correlograms showed more negative coefficients than those expected for $1 \mathrm{DC}$ with no autocorrelation whatsoever. In Buenos Aires, unlike what was observed in the other populations, the percentages of significant autocorrelation coefficients were relatively important [20\% (30\%)]. Moreover, the global correlograms (for Moran's $I$ and Geary's $c$ ) were significant for the first component. $75 \%$ of the coefficients for $1 \mathrm{DC}$ were positive. The similarity correlogram analysis using the Manhattan distance and clusterization with the UPGMA procedure showed that the 7 loci studied in every population were clustered in different ways (Fig. 4).

A way of measuring the similarity between the correlograms is to analyze the percentage of Manhattan average distance values between the variables lower than a 0.2 value. I only show the percentage obtained with Moran's $I$ index at 
Table 5. Factorial structure matrix (correlation coefficients) between cat sampling colonies and subpopulations of 4 cat populations studied with the first two axes from a Principal component analysis $(\mathrm{Q}$ type) and eigenvalues and percentage of variance from this analysis. SIG - significant, NS - no significant.

\begin{tabular}{|c|c|c|c|c|c|}
\hline \multicolumn{3}{|c|}{ Sampling colonies level } & \multicolumn{3}{|c|}{ Sampling subpopulation level } \\
\hline Localities & 1st component & 2nd component & Localities & 1st component & 2nd component \\
\hline 1 & 2 & 3 & 4 & 5 & 6 \\
\hline \multicolumn{6}{|l|}{ BARCELONA } \\
\hline A & 0.95182 & -0.15774 & A & 0.96661 & -0.21627 \\
\hline B1 & 0.85607 & 0.49938 & B & 0.99857 & 0.02590 \\
\hline B2 & 0.97098 & -0.11275 & C & 0.95689 & 0.28418 \\
\hline B3 & 0.99058 & -0.08521 & D & 0.99767 & -0.00579 \\
\hline $\mathrm{C}$ & 0.95879 & -0.02605 & $\mathrm{E}$ & 0.98378 & -0.08433 \\
\hline D1 & 0.97783 & -0.02254 & Eigenvalues & 4.81032 (SIG) & 0.13535 (NS) \\
\hline D2 & 0.98246 & -0.11979 & $\%$ Variance & 96.21 & \\
\hline E1 & 0.84968 & 0.48717 & & & \\
\hline E2 & 0.87441 & -0.38978 & & & \\
\hline E3 & 0.94902 & 0.16800 & & & \\
\hline E4 & 0.97616 & -0.15502 & & & \\
\hline Eigenvalues & 9.74365 (SIG) & $0.7513(\mathrm{NS})$ & & & \\
\hline$\%$ Variance & 88.58 & & & & \\
\hline \multicolumn{6}{|c|}{ PALMA MAJORCA } \\
\hline A & 0.95234 & 0.15345 & A & 0.96470 & 0.03094 \\
\hline B & 0.90173 & 0.26353 & B & 0.90553 & 0.18064 \\
\hline C1 & 0.96234 & -0.17303 & C & 0.96679 & -0.15342 \\
\hline $\mathrm{C} 2$ & 0.93432 & 0.32534 & D & 0.87025 & 0.43922 \\
\hline C3 & 0.82629 & -0.35405 & $\mathrm{E}$ & 0.96521 & -0.21648 \\
\hline $\mathrm{C} 4$ & 0.98560 & -0.13256 & Eigenvalues & 5.32261 (SIG) & 0.34773 (NS) \\
\hline D1 & 0.96685 & -0.20935 & $\%$ Variance & 88.71 & \\
\hline D2 & 0.98884 & -0.06834 & & & \\
\hline $\mathrm{E}$ & 0.85841 & 0.37108 & & & \\
\hline $\mathrm{F}$ & 0.96595 & -0.15174 & & & \\
\hline Eigenvalues & 8.75586 (SIG) & $0.58093(\mathrm{NS})$ & & & \\
\hline$\%$ Variance & 87.56 & & & & \\
\hline \multicolumn{6}{|l|}{ RIMINI } \\
\hline A1 & 0.97314 & -0.13801 & A & 0.98053 & -0.17068 \\
\hline A2 & 0.98219 & -0.07628 & B & 0.98390 & -0.11179 \\
\hline B1 & 0.79610 & 0.59449 & C & 0.96559 & 0.24859 \\
\hline B2 & 0.94537 & -0.23835 & D & 0.94211 & -0.31125 \\
\hline B3 & 0.95042 & -0.27642 & $\mathrm{E}$ & 0.93412 & 0.34220 \\
\hline $\mathrm{C}$ & 0.95532 & 0.07021 & $\mathrm{~F}$ & 0.97857 & 0.01114 \\
\hline D & 0.93055 & -0.34281 & Eigenvalues & 5.57965 (SIG) & $0.31753(\mathrm{NS})$ \\
\hline E & 0.92040 & 0.09709 & \% Variance & 92.99 & \\
\hline F1 & 0.97331 & 0.03024 & & & \\
\hline F2 & 0.85626 & 0.42184 & & & \\
\hline F3 & 0.99541 & -0.00411 & & & \\
\hline Eigenvalues & 9.63955 (SIG) & 0.82227 (NS) & & & \\
\hline \% Variance & 87.63 & & & & \\
\hline
\end{tabular}


Table 5 - concluded.

\begin{tabular}{lcclcc}
\hline \multicolumn{1}{c}{1} & 2 & 3 & 4 & 5 & 6 \\
\hline BUENOS AIRES & & & & & \\
A & 0.97285 & 0.08035 & $\mathrm{~A}$ & 0.98079 & 0.14389 \\
$\mathrm{~B}$ & 0.99385 & 0.04738 & $\mathrm{~B}$ & 0.97112 & 0.18670 \\
$\mathrm{C}$ & 0.89399 & 0.25920 & $\mathrm{C}$ & 0.98920 & 0.03698 \\
$\mathrm{D}$ & 0.98680 & -0.00916 & $\mathrm{D}$ & 0.91992 & -0.39027 \\
$\mathrm{E}$ & 0.91835 & -0.37008 & Eigenvalues & 3.72981 (SIG) & 0.20925 (NS) \\
$\mathrm{F}$ & 0.87455 & 0.43788 & \% Variance & 93.25 & \\
G & 0.89334 & -0.43771 & & & \\
Eigenvalues & $6.11344(\mathrm{SIG})$ & 0.59627 (NS) & & & \\
\% Variance & 87.33 & & & & \\
\hline
\end{tabular}
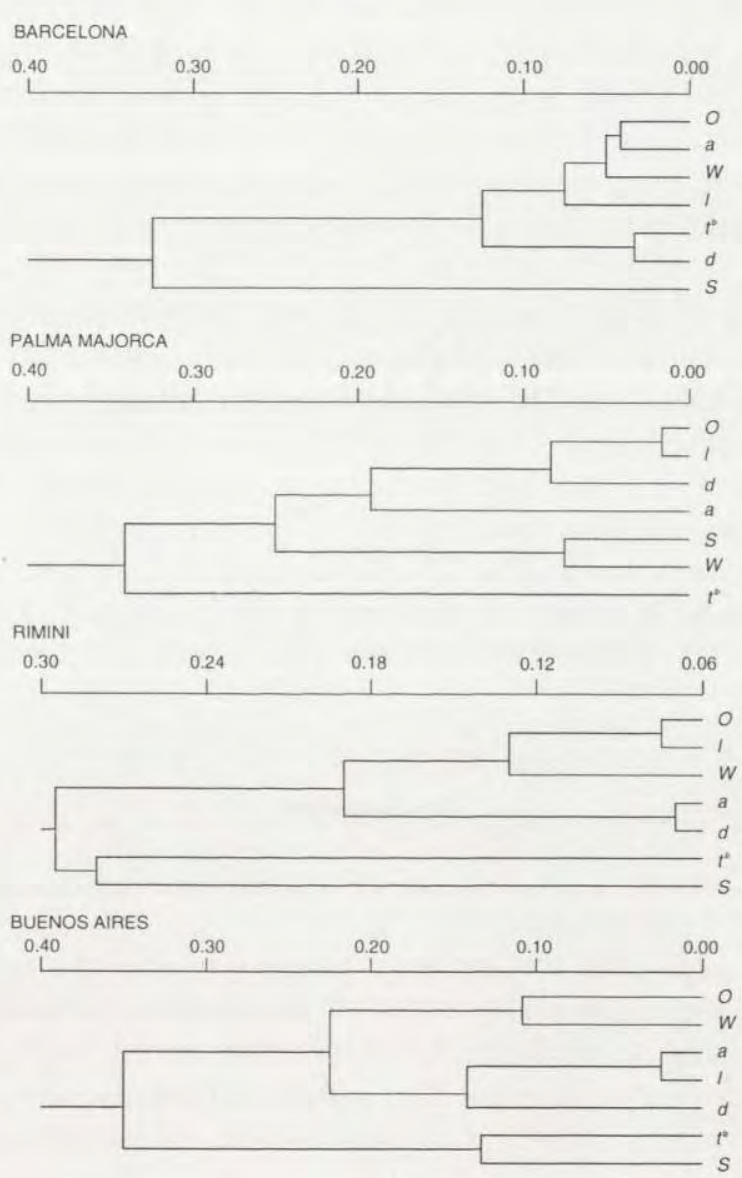

Fig. 4. UPGMA dendrograms from Manhattan distance matrix of the distance classes obtained in the spatial autocorrelation analysis with the Moran's $I$ index for the seven alleles studied in different colonies of domestic cats. 
colony level. Barcelona (66.66\%) and Rimini (42.86\%) presented higher percentages than Palma on Majorca (23.80\%) and Buenos Aires (0\%) (eg Rimini vs Buenos Aires: $\chi^{2}=11.45, \mathrm{df}=1$; Barcelona vs Palma on Majorca: $\chi^{2}=6.15, \mathrm{df}=1$; Barcelona vs Buenos Aires: $\chi^{2}=18.11, \mathrm{df}=1$, all differences significant).

The analysis of the normalized Mantel's test was interesting at colony level. At this sample level, the Nei's (1972) genetic distance matrices confronted with the geographic distance matrices offered different types of relationships in the populations studied. Rimini showed a significant negative correlation between the genetic relationship among the cat colonies in this locality and their geographic separation (Nei: $r=-0.305, p=0.035$; Monte Carlo simulation). Palma Majorca (Nei: $r=-0.177$ ) and Barcelona (Nei: $r=-0.075$ ) presented not significant negative relationship. Contrarilly, Buenos Aires (Nei: $r=0.234$ ) offered positive correlation between the genetic and geographic distances although not in a significant way.

The principal component analyses to study the contribution of the colonies and subpopulations in the populations analyzed to the genetic variance found (Table 5) strengthen some results previously shown. When I studied the contribution of the localities, I observed how the first principal component was the only significant one in all the populations studied (only component with an eigenvalue $>1$ ) (either at colonial level as at subpopulational level). This only significant component explained between $87.33 \%$ (Buenos Aires) and $88.58 \%$ (Barcelona) of the total genetic variance at colony level and between $88.71 \%$ (Palma Majorca) and $96.21 \%$ (Barcelona) of the total genetic variance at subpopulation level. The correlation between the different localities within a city and this first component was in most cases higher than $r=0.90$. For example, at colonial level, the localities that presented a lower correlation with this first principal component were: the $\mathrm{F}$ colony $(r=0.8745)$ in Buenos Aires, the $\mathrm{C} 3$ and E colonies $(r=0.8262$ and $r=0.8584$, respectively) in Palma Majorca, the B1 and F3 colonies ( $r=0.7961$ and $r=0.8562)$ in Rimini, and the B1, E1 and E2 colonies $(r=0.8560, r=0.8494$ and $r=0.8744)$ in Barcelona.

\section{Discussion}

Gene flow and correlations with certain parameters

The first basic idea that we get from this study was the relatively similarity in some aspects between the all analyzed cat populations although a great number of variables depending on demographic, historical, social, ecological and temporal parameters could be very different. The genetic differentiation observed at colony and subpopulation sample levels was very small to be compared to the one found in other mammalian species (Daly and Patton 1990, Wayne et al. 1991, Bigalke et al. 1993, Hartl et al. 1993, Lorenzini et al. 1993, Preleuthner and Pinsker 1993, Georgiadis et al. 1994). This indicated that apart from the existence of differentiated parameters between these populations, other variables are constant. 
For instance, high gene flow goes in all directions and is relativelly similar in all the populations analyzed. Due to a similar attitude towards the cats among the human beings in all these populations (at present and in the past) and due to the reproductive biology of this species, all the sample population levels estimated could have reached some genetic equilibrium between them and a overall no genetic structuration in relatively few generations due to a possible high migratory rate per generation $(m)$ in the populations studied. Recently, Chesser $(1991 \mathrm{a}, \mathrm{b})$ and Chesser et al. (1993) showed that the application of Wright's infinite island model to microgeographical levels in natural populations of social species is incorrect because the F-fixation indices are affected overall by the social structure and the reproductive tactics. Nevertheless, the influence of man, transporting cats between colonies and subpopulations within a city, could approach it to Wright's island model. Moreover, the island model results are very similar to those produced by a hierarchical model (Slatkin 1985a) and those produced by a bidimensional stepping-stone model (Crow and Aoki 1984). However, in most cases, although there are deviations from the island model, the $\mathrm{Nm}$ estimates are robust enough (Slatkin and Barton 1989). These high gene flow estimates could be explained not only because the migratory rates per generation are considerable but also because the effective population sizes of this species within the cities must be enormous. Unfortunately, there is not information about the population sizes in the cities studied here. The cat population in a city can be divided into two basic components, the owned cat population and the free cat population. I have some facts about the cat population density in some North-American cities. Some of the minimum values found were $355 \mathrm{cats} / \mathrm{km}^{2}$ for the population of Newton, $629 \mathrm{cats} / \mathrm{km}^{2}$ for the population of Charlestown, $416 \mathrm{cats} / \mathrm{km}^{2}$ for the population of Salem, and 668 cats $/ \mathrm{km}^{2}$ for the population of Urbana (Fagen and Moriarty 1976, Todd 1977b). This means that one of these two components which cause the overall size of a cat population has important dimensions. A very great number of these cats are in contact with the natural cat population (eg 200000 cats are abandoned by their owners every year in Spain and a great number of these cats are incorporated in the free populations of this species). As regards the population size of the natural cat population, I have very few facts. Nozawa et al. (1985) stated that more than 2 million cats were living freely in Japan's higgest island. Some estimates of cat density in free populations living in different cities were: 2350 cats $/ \mathrm{km}^{2}$ in Ainoshima (Japan; Izawa et al. 1982, Izawa 1984), 1000-2000 cats $/ \mathrm{km}^{2}$ in Rome (Italy; Natoli 1985a) and $200 \mathrm{cats} / \mathrm{km}^{2}$ in Portsmouth (England; Dards 1978, 1983). This shows that the cat populations within the cities have very important effective sizes. Together with the high theoretical gene flow estimates within each of the cities studied approaches relativelly each of these populations to a panmictic condition with relativelly small $G_{s t}$ values. Probably, this is the principal idea of the present work: the four cat populations studied were very similar in their genetic structures. 
Nevertheless, and with all this in mind, some little differences have been detected in certain genetic statistics between these cities. I observed that there was significant heterogeneity of certain alleles in these populations. At colony sample level, the genetic heterogenities were undistinguishable between all the populations studied. On the contrary, at subpopulation sample level, significant differences were found between the populations as regards statistics like $G_{s t}$ or $D m$. Barcelona presented the lowest genetic differentiation at this level. Rimini and Buenos Aires presented a similar internal genetic differentiation while Palma Majorca offered a slightly higher differentiation.

At subpopulation sampling level, although the amount of genetic heterogeneity was lower within the cities than at colony level (greater importance of stochactic, sampling processes and reproductive biology at this last sample structure), a greater (and in many cases significant) internal genetic differentiation between the cities studied were detected than the one found at colony level. The results obtained with these statistics seem to show that the differential action of different evolutionary agents was more likely to be fixed at subpopulation sample level than at colonial one because these agents would affect structures with greater population sizes and more persistence in time. At colony level, the action of different evolutionary agents between the different towns studied makes it more difficult to keep them fixed because the colonies were of much smaller population sizes with a considerably greater stochastic error, and they probably represent population sampling structures that are very ephemeral in time and where there are not the same possibilities (compared to subpopulation sampling level) for the genetic differences to accumulate as time passes by, as may happen at subpopulation level. Moreover, at colonial sampling level, it is possible that the differential agents in all populations are exclusively stochastic processes operating in a very similar way in all of them. On the contrary, at subpopulation level, other agents (historical, ecological) can be operating in a differential way between the populations and these different accumulated evolutionary actions may stay at these level (but not at colonial one) and be detected with the population genetics methods in use. This shows the very strong importance of sampling in various different levels within a population. Each sampling level can be affected by different sampling errors and by different evolutionary agents (see, for instance, Sokal et al. 1987).

\section{Mutant alleles and genetic differentiation}

At colony level, the 3 European populations showed that the $t^{b}$ and $l$ alleles were those which introduced most genetic heterogeneity. In the case of Buenos Aires, the alleles $t^{b}$ and $O$ were those which introducde greatest heterogeneity, being the $l$ allele, unlike what was observed in the three European populations, the one that less genetic heterogeneity introduced. At subpopulation level, in Barcelona and Rimini the $l$ and $O$ alleles were those which introduced most genetic heterogeneity being $l$ and $t^{b}$ in Palma, and $O$ and $t^{b}$ in Buenos Aires. It is 
noteworthy how, for example, at colony level, $t^{b}$ was among the alleles which introduced more heterogeneity in all populations. The explanation why some alleles introduced more genetic heterogeneity than others is not a simple question as it could be enterpreted from a selective and/or neutral point of view (Kimura 1982). It was stated previously that some alleles like $O$ and $t^{b}$ are submitted to the influence of selective agents depending on urban parameters (Dreux and Todd 1974, Clark 1975, 1976, Blumenberg 1977, Dreux 1979, Robinson 1980, 1987). In the urban environment, the $t^{b}$ allele should be favoured whereas the $O$ allele should be disfavoured. If there were ecological patches within the cities with different urban intensity levels, the influence of a diversifying selection related to these parameters could be the explanation why these alleles $\left(t^{b}\right.$ and $O$ ) offered to show higher $G_{s t}$ values. Nevertheless, this explanation is not absolutely satisfactory. Only in one case, one correlation was observed between the urban level and the frequency of $O$ allele in Barcelona (Ruiz-Garcia 1988). For the remainder populations studied no correlation was observed between the different allele frequencies and the urban levels of the different colonies and subpopulations (Murcia, Ruiz-Garcia 1991; Marseilles, Ruiz-Garcia 1994b; Ibiza, Ruiz-Garcia 1993). If there really is a selective agent depending on an urban effect, we would expect this to happen in all cities and not in just some of them. A neutralist explanation could be used if we take into account a series of facts. Each population may have had its own characteristics conditioned by its own history. The ancient mutant alleles introduced in the populations (especially before having acquired a relatively important demographic size) would have penetrated and reached the majority of subpopulations, colonies and propagules from which the actual overall population was originated and their allele frequencies would have become homogeneous as time passed by (because of a high gene flow within the population), while the mutant alleles more recently introduced could not have reached in identical way all the actual population structures. In the sampling colonies or subpopulations which have reached an important effective size it would be more difficult for them to penetrate and to reach a genetic equilibrium, so that they would show a greater heterogeneity than the former. To this, we could add the geographic heterogeneity from which these alleles come to each of the considered population (and with that different allele frequencies arrived to the new population) and if the gene flow from one population to another has temporally been constant or, on the contrary, has been sporadic. It could also be extraordinarily important if the human demographic increase (and of its eat population) was identical and symmetrical in different areas or sectors of a city or if , on the contrary, whether the different sectors of a city have increased in a different and asymmetrical way, it could be very important for the genetic heterogeneity of most modern mutant allele introduced in a city. Effectively, the $l$ and $t^{b}$ alleles are two historic "modern" alleles which could only have penetrated in the populations studied in the last centuries, the former coming from Great Britain (principally) and the latter, probably, from Asia Minor and other areas. In fact, those were in 
many cases the ones which introduced greatest genetic heterogeneity in the populations studied. It is very difficult to believe that there should se climatic differences (maxim and minim temperatures in different epochs of the year, relative humidity, etc) in different sectors or districts within the city, great enough to cause the significant genetic heterogeneity for the $\mathrm{q}(l)$ frequencies long hair) in these populations. Contrarily, in Buenos Aires, I observed a strong himogeneity for this allele. It is also difficult to believe that there should be especifically a unifying selective agent for this allele in this population and nd in other populations (because the Buenos Aires temperatures are similar to those of Barcelona, for instance). It is more likely that this allele was favouratly selected in a more or less constant way by the first (and subsequent) European colonists who settled in this area and that this favourable selection previous to the migration was maintained for a long time while the population was getting estabished from a demographic point of view. On the contrary, when this allele arrved to the European population studied here it may have found already establihed populations from a demographic and genetic point of view and this could bethe reason why the genetic heterogeneity of this allele was appreciable in these European populations. Thus, a neutralist explanation of these heterogeneity $\mathrm{s}$ feasible. Although some alleles like $t^{b}$ could have some slightly more favourabe selection coefficients than other alleles $\left(t^{+}\right)$at the same locus in an urban enviroiment, the existence of a high effective size and of a high internal gene flow woull minimize the impact of this selective action on the $t^{b}$ allele. It also is possible that each allele studied was introducced within cities in different historical moments and with different echological and demographic parameters, as differert effective population sizes $(\mathrm{Ne})$, different migration rates per generation $(m$, different number of colonist $(K)$, and different extinction rates per generation (eo). Also, these different genes could be introduced following diverse models (Slakin 1977). If the genes studied here were introduced in different historical monents with different demographic parameters and with different source of migrant and ways in which colonist were chosen, we should expect different $G_{s t}$ values foreach allele (Wade and McCauley 1988, Whitlock and McCauley 1990, Whitbck 1992). Nevertheless, nor can we completely discard that there was some diversifying selective agent for some alleles or for others unifying selection (eg $\mathrm{W}$ allele, for this last case) which are the origin of the high heterogeneities of sme alleles and/or of the high homogeneities of others, and, even, of a simultaneors action of neutralist and selective processes. Additionally, I did not know if ary of these genes was linked to other genes which were under selective pressure.

Spatial autocorrelation analysis

The spatial autocorrelation analysis showed that there was little on very little genetic structuration in the cat populations studied. It can be observecin the low percentages of significant spatial autocorrelation coefficients and in the ew genetic variables which showed a significant spatial structure. A group of eolutionary 
agents can be discarded as the principal responsables for the results I get: (1) Patterns where very few correlations are found between the genetic variable surfaces (highly different surfaces) but with correlograms showing significant and very similar autocorrelation (a high percentage of Manhattan distances between the autocorrelation coefficients of pair of variables lower than 0.1 ). These patterns are generated by stochastic processes like those of isolation-by-distance with the same population parameters affecting each of the genetic variables (Sokal and Wartenberg 1983). Generally, dissimilar patterns will reflect differences in the processes which produce the correlograms with the exeption of the mentioned pattern, because in the random processes (genetic drift) generated with the same demographic parameters, they give different and spatial surfaces independent between them but with identical correlograms because they are generated by the same variance-autocovariance structure. Changes in these population parameters will reflect changes in the correlograms (Sokal and Wartenberg 1983). As can be observed, in a great number of cases, the variables in each of the studied cat populations did not show identical correlograms so a stochastic process like isolation-by-distance is not a general explanation of the spatial variation of the studied cat populations. Moreover, if the stochastic processes were of some importance, the influencing demographic parameters in some of the genetic variables in the time would be different. Sokal et al. (1986) showed that it is typical of stochastic processes that the average correlograms are better indicators of genetic similarity declination with the geographic distance than the correlograms for single allele frequencies because the individual variations tend to annul one another. In the studied populations there was not a clear monotonic declination of genetic similarity with the geographic distance. This again proves that isolation-by-distance was of little or no importance in the cat populations within a city. This could mean that in this case there is no restriction on gene flow. In the models of isolation by distance generated by Sokal and Wartenberg (1983), all of them showed significant patterns of spatial autocorrelation. Only on one occassion correlograms were obtained where there was no spatial autocorrelation: the panmictic case. This could be more evidence that the majority of urban cat populations were near to panmixia. (2) Certain stochastic processes like the phenomenon of fission-fussion (Sokal et al. 1986) are characterized by showing a weak surface correlations and a weak parallelism of correlograms but a strong and significant spatial structure. This was not the case in the cat populations either. (3) Patterns with strong correlations between the surfaces of the allele frequencies and strong similarity in the correlograms. It may be motivated by three principal causes: (a) Correlations caused by an intrinsic factor which has an effect on the observed variables. (b) All the allele frequencies suffer the same selective pressure. (c) A diffusion gradient caused by migration with the immigrant differing in the allele frequencies from the receiving population (a great single migratory event; Sokal and Menozzi 1982, Ammerman and Cavalli-Sforza 1984). The absence of these strong correlations in these allelic surfaces and correlograms 
showed that there was no intrinsic cause which relates these alleles, that there was no single selective agent which influenced the spatial pattern of all these allele frequencies nor did the spatial distribution of these genetic characters reflect one great migratory event.

The absence of significant spatial patterns and the fact that many of these variables offered different correlograms could be explained generally as we know that these populations were relatively near to panmixia and had a high gene flow in different epochs, rates, and directions for each of the studied variables at least at colony level. We must remember, nevertheless, that the Buenos Aires's cat population showed a slighly greater amount of spatial structure than the other 3 populations.

When we analyzed the results of the correlations between the localities and the first and second principal components submitted to the spatial autocorrelation analysis, we can observe how only the population of Buenos Aires showed a statistically significant pattern for the first principal component. That is, with these results there was certain significant spatial structure of the cat colonies studied in Buenos Aires. Moreover, Buenos Aires population showed some significant positive autocorrelation coefficients for $1 \mathrm{DC}$ for some variables studied and positive correlation with the Mantel test between genetic and geographic distances although not in significant way. Possible explanations are: (1) There were individual historical, ecological and/or social-demographic factors which affected in a differential way the Buenos Aires cat population regard the other populations studied. (2) This could be due to the fact that it is the most recent population in origin and from a demographic point of view, and because there was less time for the internal gene flow to eliminate the initial differences and to homogenize in more conspicuous way the allele frequencies patterns. That is probably why, we were able to observe some alleles showing a patch pattern. The study of other South-American populations help us to discriminate if the results of Buenos Aires were due to 1st and/or 2nd explanations.

Another very interesting aspect was to compare, the degree of similarity between the correlograms between each of the used genetic variables in the populations studied. Sokal et al. $(1986,1987,1989)$ concluded that the greater is the degree of this similarity, the greater is the similarity in the evolutionary agents which affect to each of the genetic variables. Although the degree of similarity between correlograms was low in all cat populations studied, Barcelona and Rimini showed that the evolutionary agents which had operated on each of the genetic variables in question were more similar one to another than in the cat populations of Palma and Buenos Aires. A possible explanation was that a greater and/or more constant gene flow throughout the population had homogenized in an identical way the spatial response of each of the variables all over the area which was studied: greater homogeneity of response of each of the different genetic variables in presence of a evolutionary agent like gene flow. 
Only one significant correlation appeared in different populations and at different structure levels: $d$ vs $S$. Is there a selective agent which was favouring the correlation between these two alleles? It is also interesting to mention the significant negative relationship between $O$ vs $t^{b}$ for Barcelona's colonies. This negative correlation would be expected from a seleccionist point of view (Clark 1975, 1976, Blumenberg and Lloyd 1980). However, this was not observed in the remainder populations.

\section{Other genetic coefficients}

The study of the correlations between the localities and the first principal comporents was important. In all the cases only the first component had eigenvalues higher than 1 and the correlation between all localities in each of the studied cities with this first component was higher than 0.8 . This first component could represent the intense gene flow (or some other homogeneizating event) affecting all localities in different sampling population structures in a similar way in eack of the cities. Some localities (Q component principal analysis) showed correlations slightly lower than 0.9 with this first principal component and increased slightly their correlations with the second principal component. In fact, the localities less correlated with the first component were those that offered the most dfferentiated genetic profiles from the mean genetic profile of each population. This second component may represent the influence of stochastic and residual processes. However, it was easy to observe how the importance of gene flow (first component) under the stochastic and residual processes (second component was extraordinarily great. The percentage of explicative variance in the two first principal components, nevertheless, discriminated differences between the four studied populations more substantially at subpopulation level than at colonicl level. In the same way as happened when we studied the genic differertiation and gene flow statistics, the subpopulation level which implied larger and more persistent population sizes accumulated and fixed the different differertial evolutionary events which may have taken place throughout time in each of the populations and in this way discriminated better between them. On the cortrary, the colonial level represented smaller population sizes, with less probablity of temporal persistence. Thus, the differential evolutionary events between the populations were less probable to fix and, for this reason, to discriminate between the principal components at colony level in the four cities analyzed.

\section{Ethology and genetics}

Although many of the dates shown are likely the result of the association between man and cat, where the latter depends on the high mobility of the former, the reproductive biology of this species also helps to contribute and understand the genetic results obtained. On places where there is concentrated food (eg, in a city), the females form groups where their reproductive areas overlap each other 
widely, and, some groups of females even share duties and look after the litters in turn (Macdonald et al. 1988, Dards 1978). This means that in the same community there may be different females and kittens of different genetic lines without existing any territorial behaviour between them (Natoli 1985b). Moreover, $15 \%$ of the females emigrate to other groups established from their natal demes (Liberg 1981). In addition, there seem to exist evidence for the fact that the females try to avoid endogamy. According to Liberg (1983), there is a stronger tendency among females with related males in their groups to leave the place more frequently during the period of estrous than among females without related males in their groups. On the other hand, during the reproductive season, the males increase extraordinarily their dispersive ranks and they may spread their genetic characteristics over a large area without fighting seriously for the females and overlapping widely their ranks (Liberg 1980). Moreover, most of the males leave their natal groups when they reach the age of 2 or 3 years (Liberg 1980, Warner 1985) and only a few reach a reproductive status in their place of birth (Liberg 1981). Many males move continuously from one colony to another can introduce a strong "gametic dispersal" (Waser and Elliot 1991).

With all this in mind, we can explain the high gene flow estimates found and why the genetic heterogeneity, although significant in some cases for certain loci, was relativelly small in the four cities studied. All this shows that, very probably, some pathogens like the feline immunodeficiency virus (FIV; Oldmsted et al. 1992) which extermine complete cat populations, or certain new alleles should be dispersed very rapidly within an urban cat population.

Acknowledgements: The author is grateful to many people, the help and dedication offered him from a logistic and material point of view for doing this analysis. Among them, overall, must be quoted Drs A. Sanjuan (Spain), A. T. Lloyd (Ireland), K. K. Klein (USA), P. Dreux (France), R. Robinson (Great Britain), A. Kajon (Argentina), F. J. Ayala (USA), and very especially to D. Alvarez (Colombia). This work was partially supported by the grant CONVENIO No 139-94 and 140-96 (DECRETO 1742 DE 1994) between COLCIENCIAS and the author (M. Ruiz-Garcia).

\section{References}

Ammerman M. M. and Cavalli-Sforza L. L. 1984. The wave of advance model. [In: The Neolithic Transition and the genetics of populations in Europe. M. M. Ammerman and L. L. Cavalli-Sforza, eds]. Princeton University Press, Princeton: 1-314.

Anderson M. M. and Jenkins S. H. 1979. Gene frequencies in the domestic cats of Reno, Nevada: Confirmation of a recent hypothesis. Journal of Heredity 70: 267-269.

Bigalke R. C., Hartl G. B, Berry M. P. S, and Van Hensbergen H. J. 1993. Population genetics of the springbok Antidorcas marsupialis - a preliminary study. Acta Theriologica 38, Suppl. 2: 103-111.

Blumenberg B. 1977. Genetic difference and selection in domestic cat populations of the United Kingdom and former British colonies. Theoretical Applied Genetics 49: 243-247.

Blumenberg B. and Lloyd A. T. 1980. Mutant allele frequencies in the domestic cat: a preliminary discussion of selection with particular reference to the United Kingdom and Eire. Genetica 54: $17-28$. 
Borodin P. M., Bochkarev M. N., Smirnova I. S, and Manchenko G. P. 1978. Mutant allele frequencies in domestic cat populations of six Soviet cities. Journal of Heredity 69: 169-174.

Chesser R. K. 1991a. Gene diversity and female philopatry. Genetics 127: 437-447.

Chesser R. K. 1991b. Influence of gene flow and breeding tactics on gene diversity within populations. Genetics 129: 573-583.

Chesser R. K., Sugg D. W., Rhodes O. E., Novak J. M, and Smith M. H. 1993. Evolution of mammalian social structure. Acta Theriologica 38, Suppl. 2: 163-174.

Clark J. M. 1975. The effects of selection and human preference on coat colour gene frequencies in urban cats. Heredity $35:$ 195-210.

Clark J. M. 1976. Variations in coat colour gene frequencies and selection in cats of Scotland. Genetica 46: 401-412.

Committe on Standardized Genetic Nomenclature for Cats (1968). Standardized genetic nomenclature for the domestic cat. Journal of Heredity 59: 39-40.

Crow J. F. and Aoki K. 1984. Group selection for a polygenic behavioural trait. Estimating the degree of population subdivision. Proccedings of National Academy of Sciences USA 81: 6073-6077.

Daly J. C. and Patton J. L. 1990. Dispersal, gene flow, and allelic diversity betwee local populations of Thomomys bottae pocket gophers in the Coastal Ranges of California. Evolution 44: 1283-1294.

Dards J. L. 1978. Home ranges of feral cats in Portsmouth dockyard. Carnivore Genetic Newsletters 3: $242-255$.

Dards J. L. 1983. The behaviour of dockyard cats: interactions of adult males, Applied Animal Ethology 10: 133-153.

Dreux P. H. 1979. Populations rurales de chats et effet urbain. Carnivore Genetic Newsletters 3: $220-224$.

Dreux P. H. and Todd N. B. 1974. Clinal distribution of the $t^{b}$ and $O$ alleles in European domestic cats. Carnivore Genetic Newsletters 2: 177-180.

Fagen R. M. and Moriarty D. J. 1976. Domestic cat ownership survey of Urbana, Illinois (U.S.A) neighborhoods. Carnivore Genetic Newsletters 3: 21-27.

Gabriel K. R. and Sokal R. R. 1969. A new statistical approach to geographic variation analysis. Systematic Zoology 18: 259-278.

Georgiadis N., Bischof L., Templeton A., Patton J., Karesh W. and Western D. 1994. Structure and history of african elephant populations: I. Eastern and southern Africa. Journal of Heredity 85: 100-104.

Harris R. J. 1985. A primer of Multivariate Statistics. Academic Press, Orlando, Florida: 1-583.

Hartl G. B., Suchentrunk F., Nadlinger K. and Willing R. 1993. An integrative analysis of genetic differentiation in the brown hare Lepus europeaus based on morphology, allozymes, and mitochondrial DNA. Acta Theriologica 38, Suppl. 2: 33-57.

Hochberg Y. 1988. A sharper Bonferroni procedure for multiple tests of significance. Biometrika 75 : $800-802$.

Hubert L. H. and Golledge R. G. 1982. Measuring association between spatially defined variables: Tjostheim's index and some extensions. Geographical Analysis 14: 273-278.

Hubert L. H., Golledge R. G. and Costanzo C. M. 1981. Generalized procedures for evaluating spatial autocorrelation. Geographical Analysis 13: 224-233.

Isaaks E. H. and Srivastava R. M. 1989. An introduction to applied geostatistics. Oxford University Press, New York: 1-561.

Izawa M. 1984. [Ecology and social systems of the feral cats (Felis catus Linn.)]. Ph D thesis, Kuyshu University, Japan: 1-380. [In Japanese]

Izawa M., Doi T. and Ono Y. 1982. Groupping patterns of feral cat (Felis catus) living on a small island in Japan. Japan Journal of Ecology 32: 373-382.

Kaiser H. F. 1960. The application of electronic computers to factor analysis. Educational and Psychological Measurament 20: 141-151. 
Kajon A., Centron D. and Ruiz-Garcia M. 1992. Gene frequencies in the cat population of Buenos Aires, Argentina, and the possible Origin of this population. Journal of Heredity 83: 148-152.

Kimura M. 1982. Molecular evolution,protein polymorphism, and the neutral theory. Springer-Verlag, New York: $1-365$.

Lewontin R. C. 1972. The apportionment of human diversity. Evolutionary Biology 6: 381-398.

Liberg O. 1980. Spacing patterns in a population of rural free roaming domestic cats. Oikos 35: $336-349$.

Liberg O. 1981, [Predation and social behaviour in a population of domestic cats: an evolutionary perspective]. $\mathrm{Ph} \mathrm{D}$ thesis, University of Lund, Lund: 1-215, [In Swedish]

Liberg O. 1983. Courtship behaviour and sexual selection in the domestic cat. Applied Animal Ethology 10: 117-132.

Lloyd A. T. 1985. Geographic distribution of mutant allele in domestic cat populations of New England and the Canadian Maritimes. Journal of Biogeography 12: 315-322.

Lloyd A. T. 1987. History from cats and cats from history. Endeavour 11: 342-347.

Lorenzini R., Patalano M., Apollonio M. and Mazzarone V. 1993. Genetic variability of roe deer Capreolus capreolus in Italy: electrophoretic survey on populations of different origin. Acta Theriologica 38, Suppl. 2: 141-151.

MacDonald D. W., Apps P. J., Carr G. M. and Kerby G. 1988. Social dynamics nursing coalitions and infanticide among farm cats, Felis catus. Advances in Ethology (suppl. to Ethology) 28: 1-64.

Mantel N. A. 1967. The detection of disease clustering and a generalized regression approach. Cancer research 27: 209-220.

Miller R. G. 1980. Simultaneous statistical inference. Springer Verlag, New York: 1-475.

Morrill R. B. and Todd N. B. 1978. Mutant allele frequencies in the domestic cats of Denver, Colorado. Journal of Heredity 69: 131-134.

Natoli E. 1985a. Spacing patterns in a colony of urban stray cats (Felis catus) in the historic centre of Rome. Applied Animal Ethology 14: 289-304.

Natoli E. 1985b. Behavioural responses of urban feral cats to different types of urine marks. Behaviour 94: 234-243.

Nei M. 1972. Genetic distance between populations. American Naturalist 106: 283-292.

Nei M. 1973. Analysis of gene diversity in subdivided populations. Proccedings of National Academy of Sciences USA 70: 3321-3323.

Nei M., Chakravarti A. and Tateno Y. 1977. Mean and variance of $F_{s t}$ in a finite number of incompletely isolated populations. Theoretical Population Biology 11: 291-306.

Nozawa K., Fukui M. and Furukawa T. 1985. Blood-protein polymorphisms in the Japanese cats. Japanese Journal of Genetics 60: 425-439.

O'Brien S. J. 1986. Molecular genetics in the domestic cat and its relatives. Trends in Genetics 2; 137-143.

Oden N. 1984. Assessing the significance of a spatial correlogram. Geographical Analysis 16: 1-16.

Olmsted R. A., Langley R., Roelke M. E, Goekin R. M., Adjar Johnson D., Goff J., Albert J., Packer C., Laureson M. K., Caro T. M., Scheepers L., Wildt D. E, Bush M., Martenson J. S. and O'Brien S. J. 1992. World-wide prevalence of lentivirus infection of wild feline species: epidemiologic and genetic aspects. Journal of Virology 66: 6008-6018.

Preleuthner M. and Pinsker W. 1993. Depauperated gene pools in Marmota m. marmota are caused by an ancient bottlneck: electrophoretic analysis of wild populations from Austria and Switzerland. Acta Theriologica 38, Suppl. 2: 121-139.

Robinson R. 1972. Mutant gene frequencies in cats of Cyprus. Theoretical Applied Genetics 42: 293-296.

Robinson R. 1977. Genetics for cat breeders. Pergamon Press, Oxford: 1-201.

Robinson R. 1980. Evolution of the domestic cat. Carnivore Genetic Newsletters 4: 46-56.

Robinson R. 1987. Mutant gene frequencies in cats of the Greater London area. Theoretical Applied Genetics 74: 579-583. 
Robinson R. and Silson M. 1969. Mutant allele frequencies in cats of Southern England. Theoretical Applied Genetics 39: 326-329.

Rohlf F. J. 1970. Adaptive hierarchical clustering schemes. Systematic Zoology 19: 58-82.

Ruiz-Garcia M. 1988. Frecuencias alélicas mutantes en una población de gatos domésticos urbanos (Barcelona) y en una población de gatos rurales (Castelldefels rural) en Cataluña, España. Genética Ibérica 40: 157-187.

Ruiz-Garcia M. 1991. Más sobre la Genética de Poblaciones de Felis catus en la costa Mediterránea Española: Un análisis de la estructura genética de las poblaciones naturales de gatos. Evolución Biológica 5: 227-283.

Ruiz-Garcia M. 1993. Analysis of the evolution and genetic diversity within and between Balearic and Iberian cat populations. Journal of Heredity 84: 173-180.

Ruiz-Garcia M. 1994a. Genetic structure of Marseilles cat population: Is there really a strong Founder Effect? Genetic, Selection and Evolution 26: 317-331.

Ruiz-Garcia M. 1994b. Genetic profiles from coat genes of natural Balearic cat populations: An Eastern Mediterranean and Northafrican origin. Genetic, Selection and Evolution 26: 39-64.

Ruiz-Garcia M. 1997a. Genetic relationships among some new cat populations sampled in Europe: A spatial autocorrelation analysis. Journal of Genetics 76: 1-24.

Ruiz-Garcia M. 1997b. Genetic microstructure in two Spanish cat populations. I. Genic diversity, gene flow and selection. Genetic Selection and Evolution (in press).

Ruiz-Garcia M. 1997c. Genetic microstructure in two Spanish cat populations. II. Gametic disequilibrium and spatial autocorrelation. Genetic Selection and Evolution (in press).

Ruiz-Garcia M. and Alvarez D. 1996. The use of the domestic cat as an extragenic marker of the historical and commercial human movements. Brazilian Journal of Genetics 19: 184.

Ruiz-Garcia M. and Alvarez D. 1997. Cat genetic profiles in Catalonia, Spain. Brazilian Journal of Genetics 20: 215-224.

Ruiz-Garcia M. and Jordana J. 1997a. Spatial genetic structure of the "Gos d'Atura" dog breed in Catalonia (Spain). Brazilian Journal of Genetics 20: 225-236.

Ruiz-Garcia M. and Jordana J. 1997b. Spatial genetic structure from blood allozymes in the Pyrenean Brown, a rare cattle breed, in Catalonia (Spain). Hereditas (in press).

Ruiz-Garcia M. and Klein K. K. 1997. Genetic structure of domestic cat populations at Macro- and Micro-geographical levels: two examples (Catalonia, Spain, and Mid-Western USA). Journal of Genetics 76(2): 1-17.

Ruiz-Garcia M., Ruiz S. and Alvarez D. 1995. Perfiles genéticos de poblaciones de gatos domésticos (Felis catus) de la provincia de Girona (Catalunya, NE, España) y posibles relaciones genéticas con otras poblaciones europeas occidentales. Miscellànea Zoològica 18: 169-196.

Searle A. G. 1949. Gene frequencies in London's cats. Journal of Genetics 49: 214-220.

Slatkin M. 1977. Gene flow and genetic drift in a species subject to frequency local extinction. Theoretical Population Biology 12: 253-262.

Slatkin M. 1985a. Rare alleles as indicators of gene flow. Evolution 39: 53-96.

Slatkin M. 1985b. Gene flow in natural populations. Annual Review of Ecology and Systematic 16: $393-430$.

Slatkin M. and Barton N. H. 1989. A comparison of three indirect methods for estimating average levels of gene flow. Evolution 43: 1349-1368.

Smouse P. E., Long J. C. and Sokal R. R. 1986. Multiple regression and correlation extensions of the Mantel test of matrix correspondence. Systematic Zoology 35: 627-632.

Sneath P. H. and Sokal R. R. 1973. Numerical taxonomy. W. H. Freeman, San Francisco: 1-412.

Sokal R. R., Harding R. M. and Oden N. L. 1989. Spatial patterns of human gene frequencies in Europe. American Journal of Physical Anthrophology 80: 267-294.

Sokal R. R. and Menozzi P. 1982, Spatial autocorrelation of HLA frequencies in Europe support demic diffusion of early farmers. American Naturalist 119: 1-17. 
Sokal R. R. and Oden N. L. 1978. Spatial autocorrelation in biology. 1. Methodology. Biological Journal of Linnean Society 10: 199-228.

Sokal R. R., Oden N. L. and Barker J. S. F. 1987. Spatial structure in Drosophila buzzatii populations: simple and directional spatial autocorrelation. American Naturalist 129: 122-142.

Sokal R. R. and Rohlf F. J. 1981. Biometry. 2nd Edn. Freeman, New York: 1-918.

Sokal R. R., Smouse P. E. and Neel J. V. 1986. The genetic structure of a tribal population, the Yanomama Indians. Genetics. XV. Patterns inferred by autocorrelation analysis. Genetics 114: $259-287$.

Sokal R. R. and Wartenberg D. E. 1983. A test of spatial autocorrelation using an isolation by-distance model. Genetics 105: 219-237.

Takahata N. 1983. Gene identity and genetic differentiation of populations in the finite island model. Genetics 104: 497-512.

Todd N. B. 1977a. Cats and commerce. Scientific American 237: 100-107.

Todd N. B. 1977b. The dynamics of owned domestic cat populations. Carnivore Genetic Newsletters 3: $100-124$.

Todd N. B. 1978. An ecological, behavioural genetic model for the domestication of the cat. Carnivore 1: $52-60$

Wade M. J. and McCauley D. E. 1988. Extinction and recolonization: Their effects on the genetic differentation of local populations. Evolution 42: 995-1005.

Warner R. E. 1985. Demography and movements of free-ranging domestic cats in rural Illinois Journal of Wildlife Management 49: 340-346.

Waser P. M. and Elliot L. F. 1991. Dispersal and genetic structure in Kangaroo rats. Evolution 45 935-943.

Watanabe M. A. 1983. [Populational study of the fur colours in the domestic cat (Felis catus L.) from sixteen Brazilian populations]. Ph D thesis, Universidade de Sao Paulo, Brazil: 1-280. [In Brasilian]

Wayne R. K., Geoge S. B., Gilbert D., Collins P. W., Kovach S. D., Girman D. and Lehman N. 1991. A morphological and genetic study of the island fox, Urocyon littoralis. Evolution 45: 1849-1868.

Whitlock M. C. 1992. Temporal fluctuations in demographic parameters and in the genetic variance among populations. Evolution 46: 608-615.

Whitlock M. C. and McCauley D. E. 1990. Some population genetic consequences of colony formation and extinction: genetic correlations within founding groups. Evolution 44: 1717-1724.

Workman P. L. and Niswander J. D. 1970. Population studies on south western Indian Tribes. II. Local genetic differentiation in the Papago. American Journal of Human Genetics 22: 24-49.

Wright S. 1969. Evolution and genetics of populations. Vol. 2. The theory of gene frequencies. University of Chicago Press, Chicago: 1-417.

Wright M. and Walters S. 1982. El gato. Ed. Blume, Barcelona: 1-365.

Received 28 October 1996, accepted 2 September 1997. 